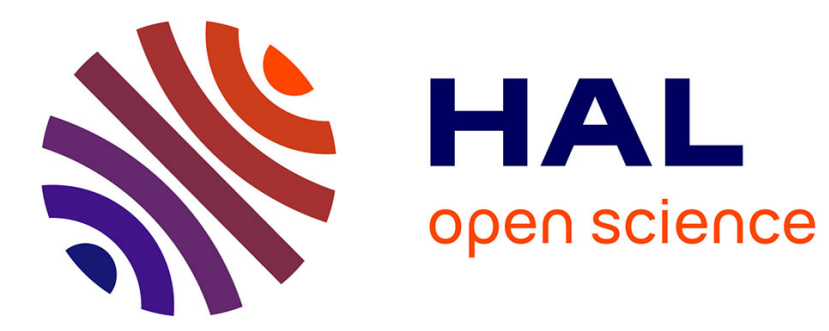

\title{
DYNAMIC STRAIN AGEING IN LiF SINGLE CRYSTALS
}

\author{
H. Fotedar, T. Stoebe
}

\section{To cite this version:}

H. Fotedar, T. Stoebe. DYNAMIC STRAIN AGEING IN LiF SINGLE CRYSTALS. Journal de Physique Colloques, 1973, 34 (C9), pp.C9-367-C9-371. 10.1051/jphyscol:1973963 . jpa-00215438

\section{HAL Id: jpa-00215438 https://hal.science/jpa-00215438}

Submitted on 1 Jan 1973

HAL is a multi-disciplinary open access archive for the deposit and dissemination of scientific research documents, whether they are published or not. The documents may come from teaching and research institutions in France or abroad, or from public or private research centers.
L'archive ouverte pluridisciplinaire HAL, est destinée au dépôt et à la diffusion de documents scientifiques de niveau recherche, publiés ou non, émanant des établissements d'enseignement et de recherche français ou étrangers, des laboratoires publics ou privés. 


\title{
DYNAMIC STRAIN AGEING IN LiF SINGLE CRYSTALS
}

\author{
H. L. FOTEDAR $(*)$ and T. G. STOEBE \\ Division of Metallurgical Engineering, University of Washington \\ Seattle, 98105 Washington, USA
}

\begin{abstract}
Résumé. - Les interactions dislocation-défaut ponctuel ont été étudiées dans des monocristaux de LiF de haute pureté contenant moins de $5 \mathrm{ppm}$ de $\mathrm{Mg}:$ par des techniques de vieillissement de contrainte dynamique. Deux mécanismes de vieillissement de contrainte ont été trouvés. Au-dessous de $200^{\circ} \mathrm{C}$, le mécanisme est un faible ancrage des dislocations par des champs de contrainte tétragonaux autour des dipôles impureté-lacune, donnant lieu à un léger accroissement du flux de contrainte après vieillissement sous contrainte. Au-dessus de $200^{\circ} \mathrm{C}$, le vieillissement de contrainte est dû à un fort ancrage des dislocations par des atmosphères ordonnées contenant des dipôles impureté-lacune et d'autres défauts ponctuels. La conséquence est la présence d'un affaissement cranté et une forte augmentation du flux de contrainte après vieillissement sous contrainte. Les effets peuvent aussi être importants sur les résultats antérieurs des études de durcissement de LiF.

Abstract. - Dislocation-point defect interactions have been investigated in high purity LiF single crystals containing less than $5 \mathrm{ppm}$ of $\mathrm{Mg}^{--}$, utilising dynamic strain ageing techniques. Two mechanisms of strain ageing have been found. Below $200^{\circ} \mathrm{C}$, the mechanism is one of weak pinning of dislocations by tetragonal strain fields around impurity-vacancy dipoles giving rise to a slight flow stress increase after ageing under stress. Above $200^{\circ} \mathrm{C}$, the strain ageing is due to the strong pinning of dislocations by ordered atmospheres containing impurity-vacancy dipoles and other point defects. This results in the presence of serrated yielding, and a large flow stress increase after ageing under stress. These effects may also be important in previously reported work hardening data in LiF single crystals.
\end{abstract}

Introduction. - Dynamic strain ageing refers to the process or processes which take place when a material is deformed plastically. This type of deformation usually manifests itself in the form of discontinuous yielding phenomena, sometimes accompanied by serrated stress-strain curves over specific ranges of temperature and strain rate.

Dynamic strain ageing was first observed in ferrous alloys [1], [2], [3] and until recently, most of the effort has been directed to understanding these systems [4], [5]. In iron and steel, dynamic strain ageing produces serrated stress-strain curves, high work hardening rates. a negative temperature and strain rate dependence of the flow stress, and a reduction of ductility [4]. Dynamic strain ageing has also been observed in other bcc alloys containing interstitial solutes [6]. [7] and in fec alloys containing both substitutional [2], [8]-[14] and interstitial impurities [12], [15], [16].

Serrated yielding has been observed in several impure ionic solids [17]. [20], and a detailed study has been made in $\mathrm{NaCl}$ [18]. In Cd-doped $\mathrm{NaCl}$ sing!e crystals, strain ageing can be described in terms of Cottrell's theory [19]. In $\mathrm{MgO}$ single crystals, Moon and Pratl [7] observed jerky fiow in the temperature range $700^{\circ-1} 000$ "C during strain rate change tests, and have attributed this to strain ageing processes occurring in this temperature interval. Strain

(*) Now at the Department of Metallurgy. Imperial College of Science and Technology, London SW 7, England. ageing was observed in impure LiF single crystals by Johnston [21], who observed that when a specimen was deformed slightly $(0.1 \%$ strain $)$ at room temperature and aged in situ at $115^{\circ} \mathrm{C}$ for $2 \mathrm{~h}$, a yield drop was observed upon re-testing. This effect was found to be sensitive to the prior heat treatment of the crystals. For more highly pure LiF crystals containing about $3 \mathrm{ppm} \mathrm{Mg}^{2+}$. Johnsion observed no strain ageing regardless of the prior heat treatment.

The present paper reports work in which yield drops are observed in high purity LiF single crystals when repeatedly deformed and aged under stress at temperature above $80^{\circ} \mathrm{C}$, and in which serrated stress-strain curves are observed above $200{ }^{\circ} \mathrm{C}$. Observations of the inter-relationship of strain ageing with work hardening is also reported. The results and causes for this behaviour are discussed below.

Experimental details. - Samples of high purity ultra-violet grade LiF single crystals of dimensions $(10 \times 4 \times 4) \mathrm{mm}^{3}$ were annealed at $700{ }^{\circ} \mathrm{C}$ for $48 \mathrm{~h}$ and furnace cooled to room temperature to standardise them and to anneal out any damage caused during cleaving. These samples contained less than 5 ppm of $\mathrm{Mg}^{2+}$ as principal impurity, as determined by a semiquantilative spectrographic analysis. These specimens were deformed in compression in an Instraon Universal Testing Machine, using a specially designed jig [22] and a resistance furnace for tests above room temperature.

Deformation was achieved at a strain rate of 
$0.002 / \mathrm{min}$, with a maximum stress sensitivity of a $1 \mathrm{gm} / \mathrm{mm}^{2}$, corresponding to a load sensitivity of $0.02 \mathrm{~kg}$.

A schematic representation of the stress-strain curve of $\mathrm{LiF}$ during a strain ageing test and during subsequent loading is shown in figure 1. Two types of test were performed, as described below.

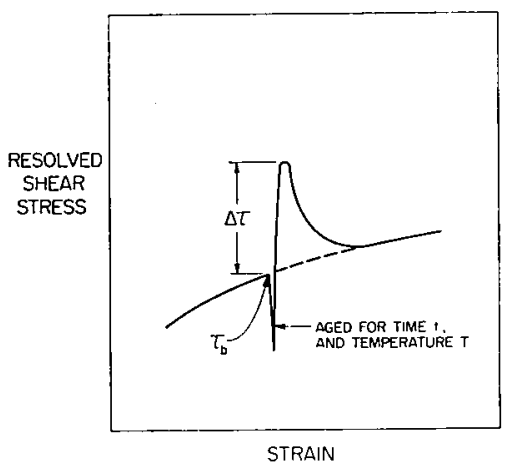

FIG. 1. - Schematic representation of a stress-strain curve during a strain ageing experiment and on subsequent re-loading.

1. Deformation at temperature $T$. Ageing at $T$. Deformation at $T$. - In these tests the deformation and the ageing temperatures are identical. The testing procedure involves the deformation of the sample to a pre-determined stress $\tau_{\mathrm{b}}$ corresponding to $\mathrm{a}$ certain strain at temperature $T$, noted in figure 1 . The cross-head is then arrested and the sample is allowed to relax under this stress for a certain ageing time, at the same temperature $T$, after which the test is resumed. The ageing time is taken as the time interval in which the cross-head is stopped. After a certain ageing period, the flow stress increment $\Delta \tau$ gives a measure of strain ageing under these ageing conditions in these crystals. The temperatures in these experiments are $100^{\circ}, 150^{\circ}, 200^{\circ}$ and $350{ }^{\circ} \mathrm{C}$ for ageing times between 5 and $30 \mathrm{~min}$.

2. Deformation at room temperature. Ageing at $T$. Deformation at roOm temperature. - This test is similar in principle to the one used by other workers [18], [23]-[25], where strain ageing techniques have been used to study the interaction of dislocations with point defects. The test procedure consists of deforming the LiF single crystal in compression at room temperature $\left(24^{\circ} \mathrm{C}\right)$ to a pre-stress $\tau_{\mathrm{b}}$, followed by ageing the specimen at a temperature $T$ for a time $t$, and then bringing the sample back to room temperature. The deformation is then continued and this procedure repeated at each $1 \%$ strain increment. The ageing temperatures used are $80^{\circ}$, $150^{\circ}, 200^{\circ}$ and $270{ }^{\circ} \mathrm{C}$, for ageing times between 5 and $30 \mathrm{~min}$.

The ageing temperatures are attained very rapidly (in less than 1 min.) by using two Sylvania Serpentine air heaters. These heaters consist of a serpentine Kanthal filament housed in a quartz tube. A conti- nuous stream of air is passed between and around the heated filament which provides the hot air used to heat the specimen. A cold air stream is used to cool the specimen to room temperature at the end of the ageing period. Typical cooling times for various temperatures range from $2 \mathrm{mn}$ for cooling from $80^{\circ} \mathrm{C}$ to $5 \mathrm{mn}$ for cooling from $270^{\circ} \mathrm{C}$.

Results. - Traces of Instron chart recordings showing serrated yielding for $\mathrm{LiF}$ samples repeatedly deformed and aged at $350{ }^{\circ} \mathrm{C}$ for 7 and $15 \mathrm{~min}$. are shown in figure 2. Serrations in the stress-strain

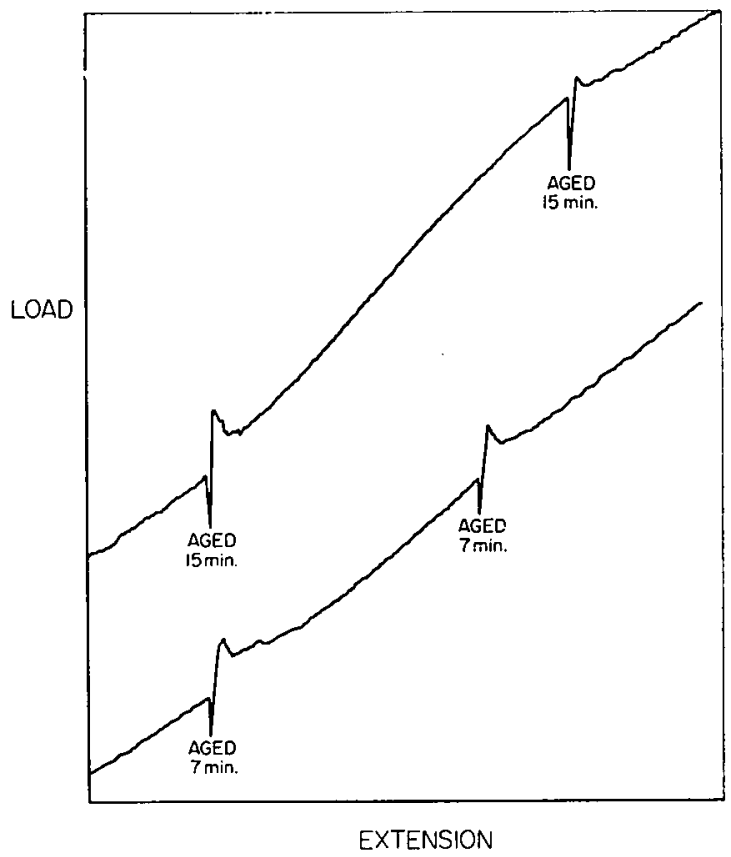

FIG. 2. - Trace of an Instron chart recording showing serrated yielding for samples repeatedly deformed and aged at $350^{\circ} \mathrm{C}$ for periods of 7 and $15 \mathrm{~min}$., as noted. Arbitrary vertical offset.

curve are particularly prominent just after the end of the ageing period when the deformation of the specimen is resumed. For deformation and ageing at temperatures below $200{ }^{\circ} \mathrm{C}$, serration in the stressstrain curves are not very prominent, although transient yield drops are observed after ageing. In general, $\Delta \tau$ increases with ageing time for type 1 experiments. Due to a considerable amount of scatter, this experimental data is difficult to analyse ; however, it does not fit the Cottrell-Bilby model [19] in the manner of the data of Brown and Pratt [18] in Cddoped $\mathrm{NaCl}$.

Using the type 2 experiment, the effect of ageing time and temperature on the strain dependence of $\Delta \tau$, the shear stress increment, has been determined. Figure 3 shows the effect of ageing temperature on $\Delta \tau$ after ageing for $15 \mathrm{~min}$. at the temperatures noted, measured on subsequent room temperature deformation. While $\Delta \tau$ is nearly independent of strain at $80^{\circ} \mathrm{C}$ and $150^{\circ} \mathrm{C}$, it clearly increases with strain at $200^{\circ} \mathrm{C}$ and does so much more drastically at $270^{\circ} \mathrm{C}$ 


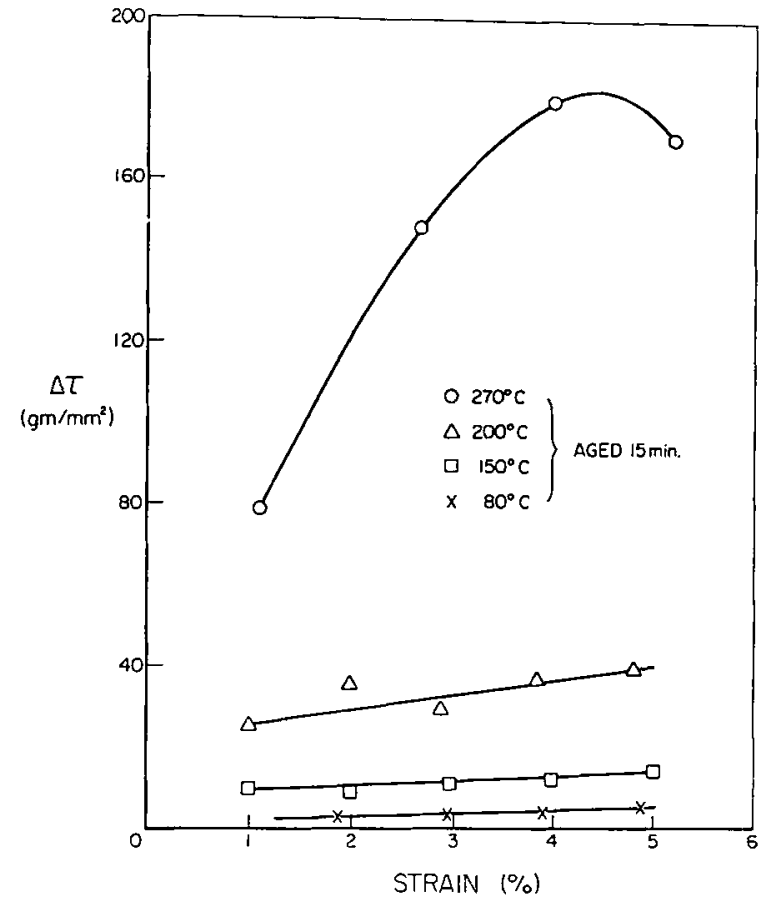

Fig. 3. - Magnitude of $\Delta \tau$ as a function of strain for ageing temperatures noted, after $15 \mathrm{~min}$. ageing; deformation carried out at room temperature.

The influence of ageing time in the type 2 experiment is shown in figure 4 , where ageing at $80^{\circ} \mathrm{C}$ and $150^{\circ} \mathrm{C}$ causes $\Delta \tau$ to remain relatively independent of the ageing time. At $200^{\circ} \mathrm{C}, \Delta \tau$ increases and then decreases, while at $270{ }^{\circ} \mathrm{C}, \Delta \tau$ decreases with ageing times over 15 min., probably due to annealing and recovery processes occurring during ageing.

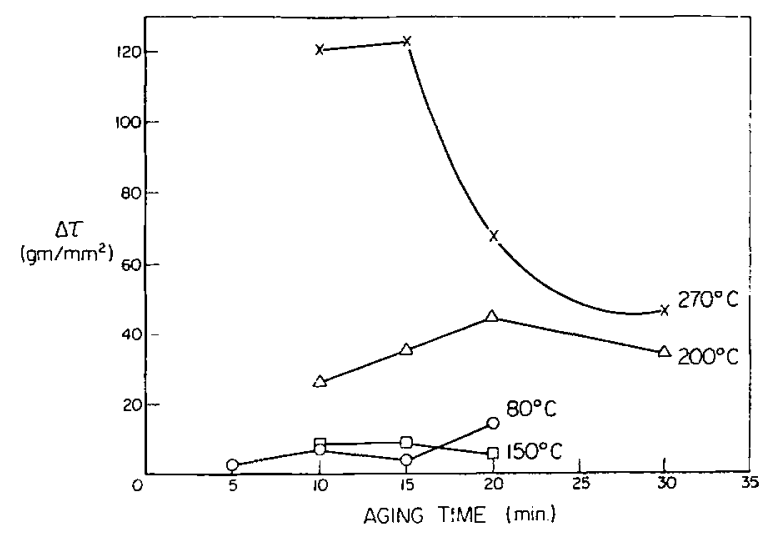

Fig. 4. - Magnitude of $\Delta \tau$ obtained after various ageing times as a function of ageing temperature, after $2 \%$ strain, with deformation occurring at room temperature.

Figure 5 shows the effect of ageing temperature on the stress-strain curves of aged, relaxed specimens compared with those of a non-aged. non-relaxed samples. Here the resolved shear stress before relaxation $\tau_{b}$ (indicated in figure 1 ) is given as a function of total strain during a scries of relaxation experiments.

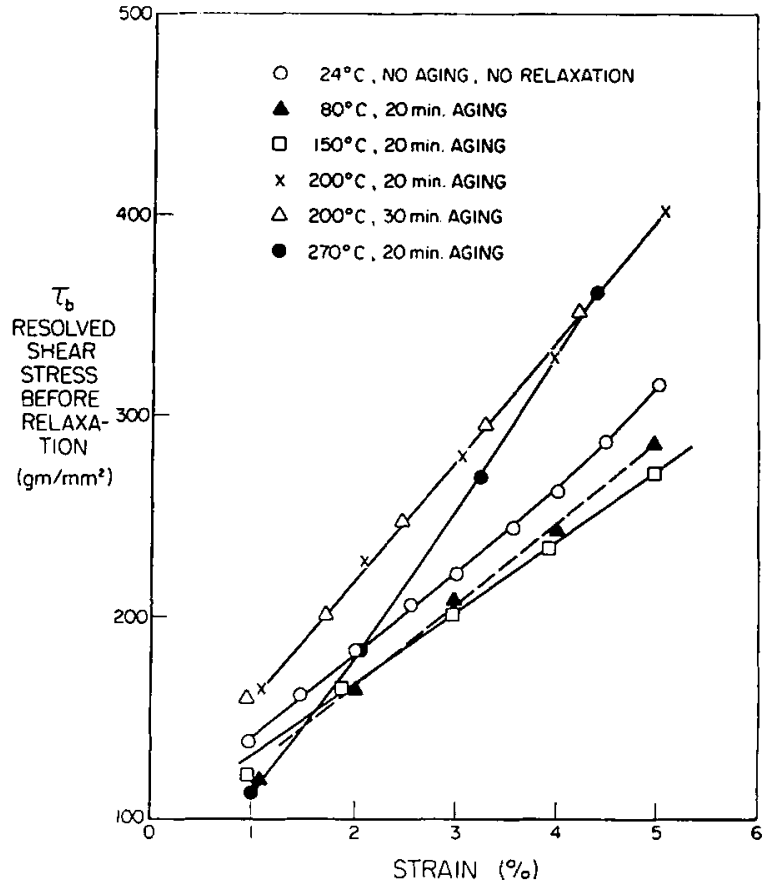

Fig. 5. - Resolved shear stress, measured just prior to relaxation, as a function of strain at various ageing temperatures, as noted.

This parameter will include an overall effect of any changes in the dislocation substructure on the stressstrain curve as a result of strain ageing and subsequent deformation. In the absence of any change in the dislocation structure, the work hardening rate, taken as the slope of such a $\tau_{b}$ vs. strain curve, should be the same as that for a sample which is not aged and not relaxed. For ageing temperatures of $80^{\circ}$ and

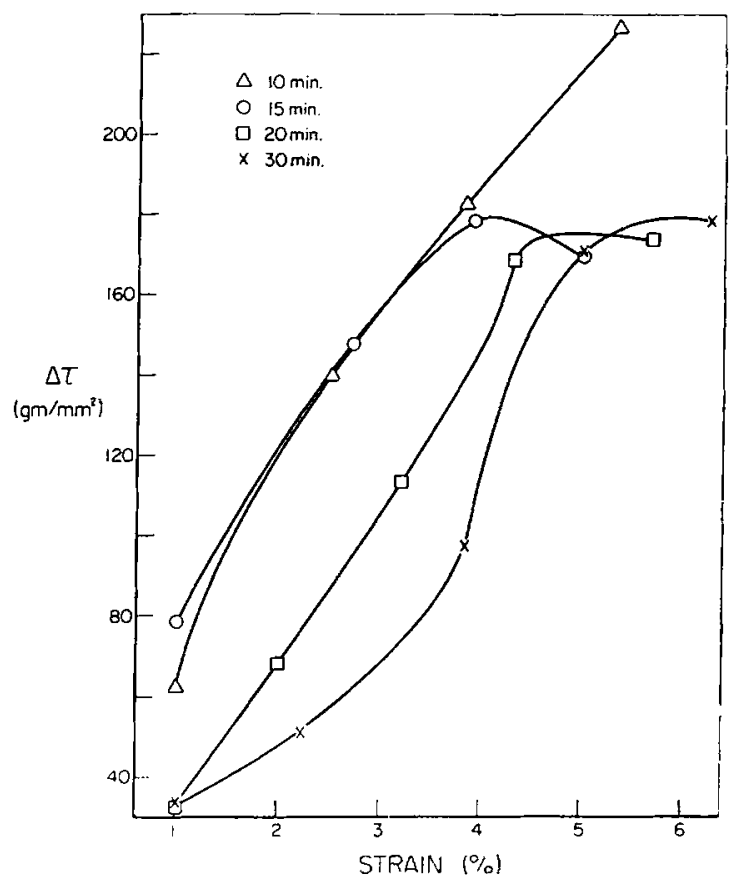

Fig. 6. - Magnitude of $\Delta \tau$ as a function of strain after various ageing times (as noted) for ageing at $270{ }^{\circ} \mathrm{C}$. 
$150^{\circ} \mathrm{C}$, the observed work hardening rates are practically the same as the room temperature values without ageing. However, for $200{ }^{\circ} \mathrm{C}$ and $270{ }^{\circ} \mathrm{C}$ ageing, work hardening rates are 1.5 and 2 times higher, possibly indicating a different mechanism of dynamic strain ageing.

Figure 6 shows the strain dependence of $\Delta \tau$ as a function of ageing time at $270{ }^{\circ} \mathrm{C}$. Generally, $\Delta \tau$ increases with strain, reaching a maximum for ageing times over $15 \mathrm{~min}$, at and above $4 \%$ strain. Further, at any particular strain $\Delta \tau$ decreases with increasing ageing times, showing overageing due to annealing effects.

Discussion. - Studies of the temperature dependence of the critical resolved shear stress (CRSS) have shown that in samples containing less than 50 ppm of divalent cation impurity, the CRSS increases with decreasing temperature in the region below $200{ }^{\circ} \mathrm{C}$ [26], [27]. This hardening has been shown to obey the Fleischer mechanism [28], [29], in which the CRSS is determined by the thermally activated passage of dislocations near rigid impurity-vacancy dipoles located close to the slip plane. The maximum temperature at which the Fleischer mechanism governs the CRSS decreases with increasing crystal purity, being $150{ }^{\circ} \mathrm{C}$ for the high purity crystals used here. Ionic conductivity results confirm the presence of impurity-vacancy dipoles as the predominant defect in the range $80-250^{\circ} \mathrm{C}$ in crystals of this purity [30].

At higher temperatures, where the Fleischer hardening mechanism is no longer present, the CRSS data becomes temperature independent [26], [27]. Here, the impurity-vacancy dipoles can reorient themselves around moving dislocations such that the dislocations will appear to drag an ordered atmosphere in its wake. In the steady state, the dislocation will experience a continuous retarding force which is independent of temperature [31].

In figure 2, the serrations in the stress-strain curve are observed because during ageing under stress at $350{ }^{\circ} \mathrm{C}$, the impurity-vacancy dipoles and some free cation vacancies, being quite mobile, diffuse to the dislocations, forming ordered atmospheres, which effectively pin the dislocations. The flow stress then increases to the higher level necessary to free the dislocations from those atmospheres. These defects also exert a dragging force on the dislocations, decreasing their mobility, which also causes an decrease in flow stress. During continued deformation, the flow stress falls, the dislocations slow down, become pinned again by atmospheres and the cycle is repeated on a smaller scale, giving rise to the observed serrated yielding phenomena.

For the room temperature deformation experiments the effects of strain ageing are shown in figure 3.6. For simplicity, two regions of dynamic strain ageing will be distinguished, one in the temperature range below $200{ }^{\circ} \mathrm{C}$ and the other operating at and above
$200{ }^{\circ} \mathrm{C}$. For ageing temperatures below $200{ }^{\circ} \mathrm{C}$, figure 3-5 show that : 1) $\Delta \tau$ is essentially independent of ageing time, 2) $\Delta \tau$ is nearly independent of strain, and 3 ) the work hardening rate is essentially the same as for unaged crystals deformed at room temperature. Based upon the CRSS and ionic conductivity data, it may be concluded that the impurity-vacancy dipole is a mjor defect contributing to this behaviour. When LiF samples are deformed at room temperature and aged at $80^{\circ} \mathrm{C}$ and $150^{\circ} \mathrm{C}$, the tetragonal strain fields around the impurity-vacancy dipoles can exert a pinning effect on the mobile dislocations. Since $\Delta \tau$ is independent of ageing time and strain, this indicates that the diffusion of dipoles to dislocations is not occurring during the ageing times used, and that very few point defects are produced upon subsequent deformation. As the observed $\Delta \tau$ values are fairly small at $80^{\circ} \mathrm{C}$ and $150^{\circ} \mathrm{C}$, the yield drops must be caused by the higher stresses needed to pull the dislocations away from surrounding dipoles. Practically no dislocation multiplication occurs at the upper yield stress since the work hardening rate in figure 5 does not change. $\Delta \tau$ will be higher for $150^{\circ} \mathrm{C}$ than for $80{ }^{\circ} \mathrm{C}$ because of a slightly increased mobility of the dipoles, which leads to the formation of dipole configurations which are more effective in pinning the dislocations. Thus for ageing below $200{ }^{\circ} \mathrm{C}$, yield drops are obtained because higher stresses are needed to pull the dislocations away from low energy configurations of impurity-vacancy dipoles. This type of pinning is weak so that $\Delta \tau$ is relatively small in this region.

After ageing at $200^{\circ} \mathrm{C}$ and $270^{\circ} \mathrm{C}$, the following are observed : 1) $\Delta \tau$ increases with strain, indicating that defects such as vacancies are being produced during deformation, 2) $\Delta \tau$ increases with ageing time, showing that the process is diffusion controlled and 3 ) the work hardening rate is higher than that resulting from room temperature deformation with no ageing. In addition it is generally found that the CRSS is independent of temperature above $200^{\circ} \mathrm{C}$, indicating that thermal activation alone helps dislocations to overcome short range barriers, without the assistance of stress.

In thermal equilibrium above $200{ }^{\circ} \mathrm{C}$, LiF crystals contain impurity-vacancy dipoles, free cation impurities and cation vacancies. When these crystals are repeatedly deformed at room temperature and aged at $200^{\circ} \mathrm{C}$ and $270{ }^{\circ} \mathrm{C}$ long-range diffusion of impurity-vacancy dipoles and vacancies can occur, and during ageing these defects can form atmospheres on the dislocation lines [31], [32]. The probability of pinning by these atmospheres is strong, so that very few mobile dislocations are left after each ageing. Since the strain rate depends upon the product of mobile dislocation density and the dislocation velocity [33] the stress rises in order to maintain the strain rate constant until the multiplication of dislocations occurs. When this happens, the stress drops 
until work hardening takes over. $\Delta \tau$ at $270^{\circ} \mathrm{C}$ is of the order of the yield stress or greater: the very high flow stress and work hardening rates must be the result of the catastrophic dislocation multiplication occurring after ageing at this temperature.

Prolonged ageing at higher temperatures results in overageing as is shown in figures 4 and 6 . Overageing at $270{ }^{\circ} \mathrm{C}$ manifests itself in the decrease of $\Delta \tau$ at higher ageing times, due to various recovery processes such as the annealing of vacancies or the thermally activated climb of edge dislocations occurring during ageing.

One can therefore conclude that there are two mechanisms that govern the dynamic strain ageing behaviour of pure LiF single crystals. Below $200^{\circ} \mathrm{C}$, the interaction of dislocations with impurity-vacancy dipoles controls the process, and since this interaction is predominantly short-range in nature, it leads to a weak pinning effect. Above $200^{\circ} \mathrm{C}$, there is a strong pinning of dislocations by ordered atmospheres of impurity-vacancy dipoles and point defects, which are long range in nature. The overall significance of these results becomes apparent by comparison with dynamic strain ageing results in other systems. In iron containing interstitial impurities, dynamic strain ageing is observed in the region where the CRSS is independent of temperature and strain rate [4]. This is also true in $\mathrm{MgO}$ [20], $\mathrm{NaCl}$ [18], [35] and $\mathrm{CaF}_{2}$ [17] single crystals, as well as in the $\mathrm{LiF}$ single crystals of the present work. Furthermore, LiF also shows an increase in the rate of work hardening with temperature in the dynamic strain ageing region above $100^{\circ} \mathrm{C}[34]$, similar to the case of iron, where the increase in work hardening in the serrated region is due to the enhancement of the dislocation multiplication rate as a result of dislocation pinning by solutes. In LiF this increase in the work hardening rate has been considered to be due to the temperature dependence of multiple cross glide and the activation of secondary slip systems at high temperatures [34]. However. some contribution 10 the work hardening rate increase by dislocation mutliplication due to dynamic pinning effect cannot be entirely ruled out.

Acknowledgments. - The authors wish to thank Dr. M. Srinivasan for helpful comments during this work and during preparation of the manuscript. This work was supported by the NASA Ceramic Materials Research Program at the University of Washington.

\section{References}

[1] Cottrell, A. H, Phil. Mag. 74 (1953) 829

[2] Portevin, A. and Le Chatelier, F., C. R. Hebd. Séan. Acud. Sci. 176 (1923) 507.

[3] NaKada, Y. and KeH, A. S., Acta Met. 15 (1967) 879.

[4] KeH, A. S., Nakada, Y. and Leslie, W. C., in Dislocation Dynamics, ed. Rosenfield et al. (McGraw-Hill, New York) 1968, 381.

[5] Bergstrom, Y. and Roberts, W., Acta Met. 19 (1971) 815.

[6] PINk, E., Trans. AIME 245 (1969) 2597.

[7] RaFfo, R. L., ASM Trans. Quarterly 62 (1969) 846.

[8] LUBHAN, J. D., Trans. AIME 185 (1949) 702.

[9] MCReynolds, A. W., Trans. AIME 185 (1949) 32.

[10] Russil, B., Phil. Mag. 8 (1963) 615.

[11] Brindley, B. J, and Worthington, P. J., Acta Met. 17 (1969) 1357.

[12] Jenkins, C. F. and Smith, G. V., Trans. AIME 245 (1969) 2149

[1.3] Brindl.ty, B. J. and Worthington, P. J., Met. Rel. 145 (1970) 101

[14] MсCоRмick, P. G., Phil. Mag. 23 (1971) 949.

[15] SONON, D. E. and Smith, G. V,, Trans. AIME 242 (1968) 1527.

[16] Boniszewski, T. and Smith, G. V., Acta Met. 11 (1963) 165.

[17] Roy, C., Ph. D. Thesis, University of London (1962).

[18] Brown, L. M. and PratT, P. L., Phil. Mag. 8 (1963) 717.
[19] Cottrell, A. H. and Bilby, B. A., Proc. Phys. Soc. Lond. A 62 (1949) 49.

[20] Moon, R. L. and Pratt, P. L., Proc. Brit. Ceram. Soc. 15 (1970) 203.

[21] Johnston, W. G., J. Appl. Phys. 33 (1962) 2716.

[22] Pascoe, R. T., Radford, K. C., Rawlings, R. D. and Newey, C. W. A.. J. Sci. Instrim. 44 (1967) 366.

[23] Birnbaum, H. K. and Tuler, F. R., J. Appl. Phys. 32 (1961) 1403

[24] Birnbaum, H. K., J. Appl. Phys. 33 (1962) 750.

[25] Birnbaum, H. K., $J$. Appl. Phys. 34 (1963) 2175.

[26] Fotedar, H. L., Ph. D. Thesis, University of Washington (1971).

[27] Reppich, B., Acta Met. 20 (1972) 557.

[28] FleisCHer, R. L., Acto Mot. 10 (1962) 835.

[29] Fleischer, R. L., J. Appl. Phys. 33 (1962) 3504.

[30] Stoebe, T. G. and Pratt, P. L., Proc. Brit. Ceram. Soc. 9 (1967) 118

[31] Pratt. P. L., Chang, R. and Newey, C. W. A., Appl. Phis. Le't. 3 (1963) 83.

[32] Shoeck, G. and Seeger, A., Acta Met. 7 (1959) 469.

[33] COTTRELL, A. H., The relation between the structure and mechanical properties of metals 2455 (N. P. L. Teddington) 1963.

[34] Fotedar, H. L. and Stoebe, T. G., Phil. Mag. 23 (1971) 859.

[35] NewEy, C. W. A., Ph. D. Thesis, University of Birmingham, 1959. 